\title{
Factors for Negative Result in Serum Anti- Helicobacter pylori IgG Antibody Test in Adult Subjects With Nodular Gastritis: A Single-center Study
}

Kyoichi Adachi ${ }^{1}$, Kanako Kishi ${ }^{1}$, Utae Sakamoto ${ }^{1}$, Tomoko Mishiro ${ }^{1}$, Eiko Okimoto ${ }^{2}$, Norihisa Ishimura ${ }^{2}$ , Shunji Ishihara ${ }^{3}$

1. Health Center, Shimane Environment and Health Public Corporation, Matsue, JPN 2. Second Department of Internal Medicine, Shimane University Faculty of Medicine, Izumo, JPN 3. Gastroenterology, Shimane University Hospital, Izumo, JPN

Corresponding author: Kyoichi Adachi, adachi@kanhokou.or.jp

\begin{abstract}
Aim: Nodular gastritis has been demonstrated to be strongly associated with Helicobacter pylori infection. The present retrospective study was performed to elucidate factors related to a negative serum antibody test result in adults with nodular gastritis.
\end{abstract}

Materials and methods: We investigated $116 \mathrm{H}$. pylori-positive subjects endoscopically diagnosed with nodular gastritis and subjected to a serum anti- $H$. pylori immunoglobulin $\mathrm{G}(\mathrm{IgG})$ antibody test. The degree of gastric mucosal atrophy and the presence of spotty redness in the gastric body and fornix were carefully determined by observations of endoscopic images.

Results: Of the 116 investigated subjects, 108 were positive and 8 negative in serum anti- $H$. pylori IgG antibody test results. The degree of gastric mucosal atrophy was mild in seven among eight seronegative cases. The levels of pepsinogen II in serum in patients with negative antibody test findings were significantly lower as compared to those found positive, while the pepsinogen I/II ratio tended to be higher in subjects shown negative by the test. Only 1 of 69 with spotty redness was negative in serum anti-H. pylori IgG antibody testing, while 7 of 47 without spotty redness were negative. Multiple logistic regression analysis of subjects with a negative test result revealed that the absence of spotty redness shown by endoscopy was a significant risk factor.

Conclusion: The absence of spotty redness, which may reflect the degree of gastric body inflammation, is a significant factor indicating increased risk for a negative serum anti- $H$. pylori IgG antibody test result in subjects with nodular gastritis.

Review began 05/19/2021 Review ended 06/03/2021 Published 06/14/2021

\section{() Copyright 2021}

Adachi et al. This is an open access article distributed under the terms of the Creative Commons Attribution License CC-BY 4.0., which permits unrestricted use, distribution, and reproduction in any medium, provided the original author and source are credited.
Categories: Gastroenterology, Infectious Disease

Keywords: nodular gastritis, helicobacter pylori, serologic test, gi endoscopy, endoscopic finding

\section{Introduction}

Nodular gastritis is endoscopically characterized by an unusual small granulated pattern, initially described as a "gooseflesh phenomenon" [1]. The histological features of nodular gastritis are hyperplasia of lymphoid follicles with germinal centers in the proper lamina of the stomach [1,2]. Several investigators have demonstrated that the condition is strongly associated with Helicobacter pylori infection in both children and adults, and nearly, all individuals with nodular gastritis shown by endoscopy are considered to have an $H$. pylori infection $[1,3-6]$.

An H. pylori infection is known to cause several types of gastrointestinal diseases, including gastritis, peptic ulcers, and gastric cancer [7-9], thus various diagnostic methods have been developed to precisely diagnose that infection [10-12]. Among the available methods, a serologic test for $H$. pylori is easily performed using obtained serum samples for both epidemiologic studies involving large numbers of subjects as well as in clinical practice for individual patients. The recently introduced anti-H. pylori immunoglobulin G (IgG) antibody detection kit SphereLight H. pylori antibody J ${ }^{\circledR}$ (Fujifilm Wako Pure Chemical Industries, Ltd., Osaka, Japan) was developed using antigens from $H$. pylori strains derived from Japanese patients. The sensitivity of this kit was demonstrated to be higher than that of another antibody detection kit popularly used in Japan [13-16]. However, we have found that some patients without a past history of eradication therapy for $H$. pylori show a negative result in the SphereLight $H$. pylori antibody J test, even though they have endoscopic evidence of nodular gastritis. Therefore, we performed the present retrospective study to elucidate factors related to a negative result in serum anti-H. pylori IgG antibody test in adults with nodular gastritis. 


\section{Materials And Methods}

The present subjects were individuals who visited the Health Center of Shimane Environment and Health Public Corporation for a detailed medical checkup examination between April 2014 and March 2018, since the newly developed $H$. pylori IgG antibody kit, SphereLight $H$. pylori antibody ${ }^{\circledR}$, was started to use for detection of serum $H$. pylori antibody from April 2014 in our institute. The majority were socially active and productive and considered to be socioeconomically middle class. During the study period, 17,727 subjects (11,664 males, 6,063 females; mean age 52.8 years) underwent an upper GI endoscopic examination, of whom 147 (61 males, 86 females) were endoscopically diagnosed with nodular gastritis (Figure 1). Of these 147 subjects, 125 were investigated by serum anti-H. pylori IgG antibody test in our institute. Of these 125 cases, 108 were diagnosed as positive for $H$. pylori infection and 17 showed negative anti-H. pylori IgG antibody test. We recommended 17 cases, whose anti-H. pylori IgG antibody test were negative, to perform other diagnostic methods, such as urea breath test or stool antigen test. Eight cases were diagnosed as positive of $H$. pylori infection by urea breath test $(\mathrm{n}=2)$, histology $(\mathrm{n}=2)$, or following anti- $H$. pylori IgG antibody test $(\mathrm{n}=4)$. The other two cases were not diagnosed as positive of $H$. pylori infection even after performing other diagnostic methods. We could not determine the status of $H$. pylori infection in seven cases, since they did not undergo the following medical checkup in our institute. Therefore, $116 \mathrm{H}$. pyloripositive cases with nodular gastritis were analyzed in this study. None had a history of eradication therapy for $H$. pylori infection, which was carefully confirmed by a trained public health nurse. In addition, none had received an anti-secretory medication, such as proton pump inhibitors and $\mathrm{H} 2$ receptor antagonists, nor had severely abnormal findings in renal and liver function testing.

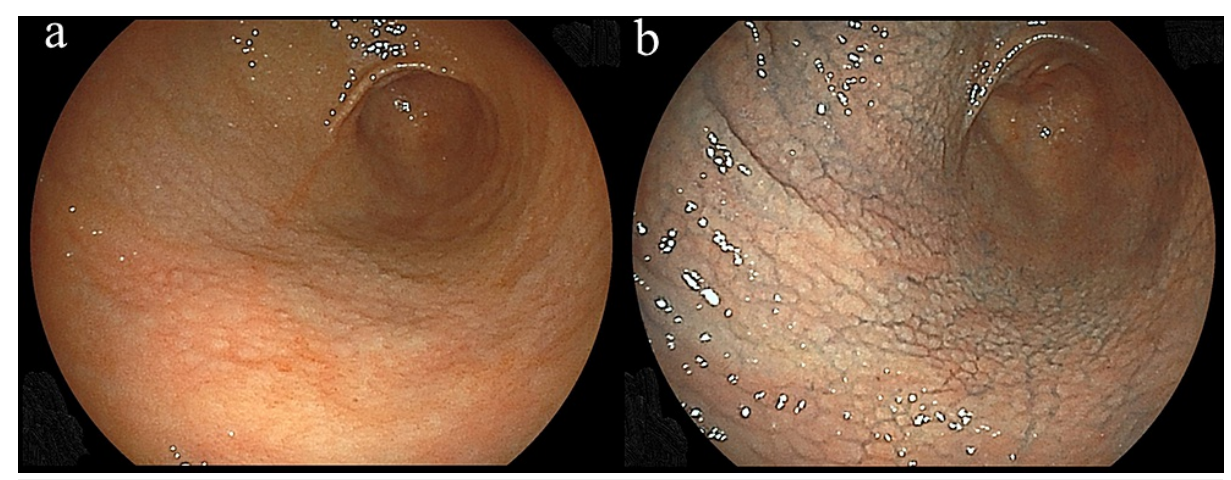

FIGURE 1: Endoscopic images of antral nodular gastritis.

(a) White light image and (b) image after Indigo carmine spraying. The presence of nodular gastritis could be easily identified after Indigo carmine spraying.

Detection of the serum anti-H. pylori IgG antibody was performed using a SphereLight H. pylori antibody ${ }^{\circledR}$ kit. The antibody titer was automatically measured using a chemiluminescent enzyme immunoassay method, with a concentration of $\geqslant 4.0 \mathrm{U} / \mathrm{ml}$ defined as positive, according to the manufacturer's instruction sheet. The sensitivity and specificity of this cut-off value were reported to be $97.5 \%$ and $98.6 \%$, respectively [16]. Serum levels of pepsinogen I and II were voluntarily investigated at medical checkups in 20 cases among 108 study subjects. Therefore, we analyzed these levels and the pepsinogen I/II ratio in those cases. Serum levels of pepsinogen I and II were examined by chemiluminescent enzyme immunoassay method with SphereLight pepsinogen I and II kits.

All upper endoscopic examinations were performed by licensed experienced endoscopists using an EG530NW, EG-530NP, or EG-L580NW endoscope (Fujifilm, Tokyo, Japan). A diagnosis of nodular gastritis was confirmed when the characteristic small granulated pattern was observed in the stomach, with indigo carmine spraying performed to detect its presence in all suspected cases (Figure 1).

The degree of gastric mucosal atrophy was evaluated using the classification of Kimura and Takemoto, in which gastric mucosal atrophy is classified into six groups (C1, C2, C3, O1, O2, O3) [17]. Three expert endoscopists simultaneously reviewed endoscopic images from all subjects, and the diagnosis of nodular gastritis and degree of gastric mucosal atrophy were determined by consensus.

Statistical analyses were performed using chi-square, Fisher's exact test, Mann-Whitney U tests, and multiple logistic regression analysis. All calculations were done using the Stat View 5.0 software program (Abacus Concepts Inc., Berkeley, CA, USA) for Macintosh, with $\mathrm{P}<0.05$ considered to indicate statistical significance.

This study was performed in accordance with the Declaration of Helsinki, and the protocol was approved by the ethics committee of the Shimane Environment and Health Public Corporation (IRB no. 2017-3). Written 


\section{Cureus}

informed consent indicating that clinical data would be used for a clinical study without the release of individual information that was obtained from all subjects before performing the medical checkup examinations.

\section{Results}

Of the $116 \mathrm{H}$. pylori-infected study subjects with nodular gastritis shown by endoscopy, 108 were positive and 8 were negative in a serum anti-H. pylori IgG antibody test. The characteristics of subjects with positive and negative results in the antibody test are shown in Table 1.

\begin{tabular}{|c|c|c|c|}
\hline & \multicolumn{2}{|c|}{ Serum anti-H. pylori antibody test } & \multirow{2}{*}{ P-value } \\
\hline & Positive & Negative & \\
\hline Gender (male/female) & $42 / 66$ & $4 / 4$ & 0.711 \\
\hline Age (years) & $45.0 \pm 8.0$ & $41.5 \pm 2.7$ & 0.293 \\
\hline \multicolumn{4}{|l|}{ Gastric mucosal atrophy } \\
\hline Mild & 76 & 7 & \multirow[t]{2}{*}{0.437} \\
\hline Moderate to severe & 32 & 1 & \\
\hline Pepsinogen I (ng/ml) ${ }^{\dagger}$ & $80.0 \pm 24.3$ & $64.3 \pm 14.6$ & 0.219 \\
\hline Pepsinogen II (ng/ml) ${ }^{\dagger}$ & $19.4 \pm 7.7$ & $10.1 \pm 2.9$ & 0.023 \\
\hline Pepsinogen I/II ratio ${ }^{\dagger}$ & $4.6 \pm 1.7$ & $6.5 \pm 0.6$ & 0.052 \\
\hline \multicolumn{4}{|l|}{ Spotty redness ${ }^{\ddagger}$} \\
\hline Presence & 68 & 1 & \multirow[t]{2}{*}{0.00} \\
\hline Absence & 40 & 7 & \\
\hline
\end{tabular}

\section{TABLE 1: Comparison between positive and negative serum anti-H. pylori antibody test results in} subjects with nodular gastritis shown by endoscopy.

Values are expressed as the mean \pm SD or number of subjects. Gastric mucosal atrophy was evaluated using the classification of Kimura and Takemoto (C1-C2: mild, C3-O1: moderate, O2-O3: severe gastric mucosal atrophy). ${ }^{\dagger}$ Pepsinogen I, II, and the ratio of I/II were examined in 16 cases shown positive and four cases shown negative in serum anti-H. pylori antibody test results. ₹Spotty multiple tiny reddish spots in fundic gland region. Typical spotty redness was defined as tiny reddish lesions $<1 \mathrm{~mm}$ in diameter occurring in abundance on the cardiac side of the fundic gland region.

The degree of gastric mucosal atrophy was mild in seven among eight seronegative cases. Only 1 subject with a higher graded (moderate, severe) gastric mucosal atrophy had a negative serum anti-H. pylori IgG antibody test result, whereas 7 (8.4\%) of 83 with mild gastric mucosal atrophy had negative test results. Additionally, the levels of pepsinogen II in serum in patients with negative antibody test findings were significantly lower as compared to those found positive, while the pepsinogen I/II ratio tended to be higher in subjects shown negative by the test. The distribution of serum titers revealed by the anti-H. pylori IgG antibody test in these subjects is shown in Table 2 . 


\section{Cureus}

\begin{tabular}{|c|c|c|c|c|}
\hline \multirow{2}{*}{ Serum antibody titer } & \multirow{2}{*}{ Total } & \multicolumn{3}{|c|}{ Gastric mucosal atrophy ${ }^{\dagger}$} \\
\hline & & Mild & Moderate & Severe \\
\hline$<1.0$ & 0 & 0 & 0 & 0 \\
\hline $1.0-1.9$ & $1(0.8)$ & $1(1.2)$ & 0 & 0 \\
\hline $2.0-2.9$ & $1(0.8)$ & $1(1.2)$ & 0 & 0 \\
\hline $3.0-3.9$ & $6(5.2)$ & $5(6.0)$ & 1 (3.1) & 0 \\
\hline $4.0-9.9$ & $18(15.5)$ & $17(20.5)$ & $1(3.1)$ & 0 \\
\hline $10.0-39.9$ & $59(50.9)$ & $38(45.8)$ & $20(62.5)$ & $1(100)$ \\
\hline$\geq 40.0$ & $31(26.7)$ & $21(25.3)$ & $10(31.3)$ & 0 \\
\hline
\end{tabular}

\section{TABLE 2: Distribution of serum titers of anti-H. pylori antibody in subjects with endoscopic nodular gastritis.}

Values are expressed as the number of subjects. Numbers in parentheses indicate the percentage. ${ }^{\dagger}$ Gastric mucosal atrophy was evaluated using the classification of Kimura and Takemoto (C1-C2: mild, C3-O1: moderate, O2-O3: severe gastric mucosal atrophy).

Subjects with an H. pylori infection have been reported to have several characteristic endoscopic findings, including diffuse redness, spotty redness, mucosal swelling, enlarged folds, and sticky mucous, as well as gastric mucosal atrophy and nodular changes [5,18-20]. However, endoscopic findings of mucosal swelling, enlarged folds, and sticky mucous were rarely observed in the present subjects with nodular gastritis, and the presence or absence of diffuse redness could not be clearly determined, whereas we noted spotty redness in the body and fornix of the stomach shown by endoscopy (Figures 2 and 3). Such an endoscopic finding of spotty redness was observed in 69 (59.5\%) of our 116 subjects, of whom only 1 (1.4\%) was negative in the serum anti-H. pylori IgG antibody test. In contrast, 7 (14.9\%) of the 47 without spotty redness were negative in the antibody test. Thus, there was a significant difference in the rate of positive findings between subjects with and without spotty redness (Table 1). In multiple logistic regression analysis findings of subjects negative for the serum anti-H. pylori antibody test, the absence of spotty redness in the stomach shown by endoscopy was a significant risk factor for a negative antibody test result (Table 3).

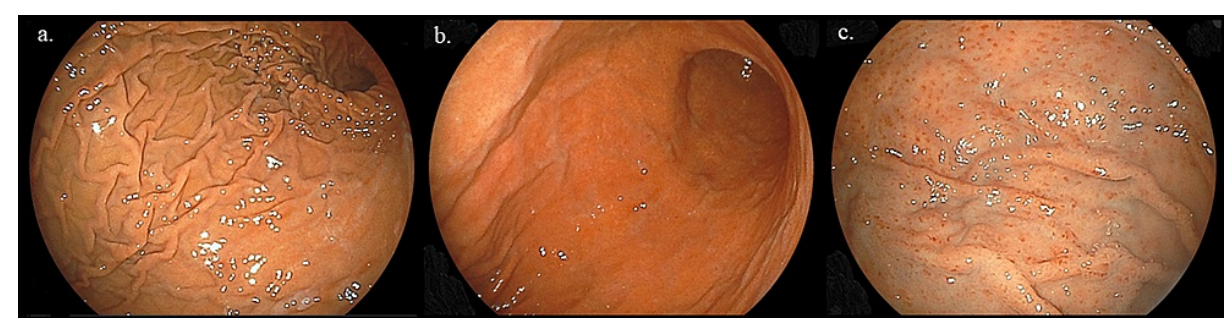

FIGURE 2: Endoscopic images of the cases with and without H. pylori infection.

(a) Normal gastric body without diffuse redness in cases without $H$. pylori infection, (b) diffuse redness of gastric body in cases with $\mathrm{H}$. pylori infection, and (c) spotty redness of fornix in the case with $\mathrm{H}$. pylori infection. The presence or absence of diffuse redness could not be clearly determined endoscopically, whereas the presence of spotty redness could be easily identified. 


\section{Cureus}

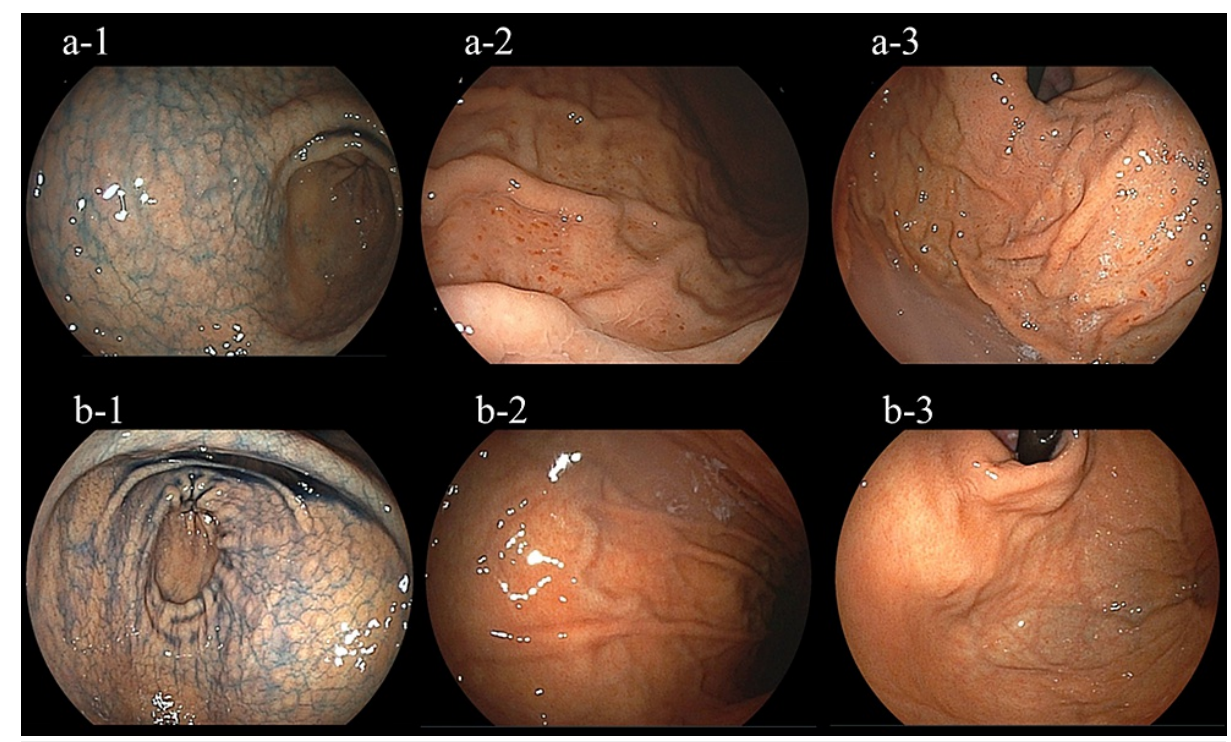

FIGURE 3: Endoscopic images of representative subjects with nodular gastritis.

Case 1: Representative subject, a 48-year-old male. Endoscopy revealed antral nodular gastritis based on indigo carmine spraying findings (a-1), and the presence of spotty redness in the body (a-2) and fornix (a-3).

Case 2: Representative subject, a 39-year-old female. Endoscopy revealed antral nodular gastritis based on indigo carmine spraying findings (b-1), and the absence of spotty redness in the body (b-2) and fornix (b-3).

Serum anti-H. pyloriantibody test in case 1 was positive and that in case 2 was negative.

\begin{tabular}{|c|c|c|c|}
\hline & Odds ratio & $95 \% \mathrm{Cl}$ & P-value \\
\hline Gender (male) & 1.700 & $0.357-8.092$ & 0.505 \\
\hline Age (increment of 1 year) & 0.924 & $0.817-1.044$ & 0.204 \\
\hline Mild gastric mucosal atrophy ${ }^{\dagger}$ & 0.497 & $0.034-7.269$ & 0.609 \\
\hline Spotty redness (absence) & 16.475 & $1.366-198.755$ & 0.027 \\
\hline
\end{tabular}

TABLE 3: Multiple logistic regression analysis of subjects found negative in serum anti-H. pylori antibody testing.

${ }^{\dagger}$ Gastric mucosal atrophy was evaluated using the classification of Kimura and Takemoto (C1-C2: mild, C3-O1: moderate, O2-O3: severe gastric mucosal atrophy). Odds ratios were calculated using mild gastric mucosal atrophy in comparison with moderate and severe.

\section{Discussion}

An H. pylori infection can lead to a variety of gastrointestinal diseases, such as gastritis, peptic ulcers, and gastric cancer [7-9], thus eradication therapy is widely recommended to prevent their occurrence [21-23]. As a result, it is very important to accurately diagnose $H$. pylori infection in clinical situations, with several different invasive and non-invasive methods available [10-12]. Among those, serologic tests are widely used for both epidemiologic studies and in clinical practice, as they are easily performed in a relatively short period of time with obtained serum. Furthermore, the sensitivity and specificity for the diagnosis of $H$. pylori infection have been reported to range from $80 \%$ to $90 \%$ [10]. The diagnostic accuracy of serological tests for $H$. pylori in Japanese subjects has been repeatedly demonstrated to increase when using kits derived from antigens of $H$. pylori strains obtained from Japanese patients [24-26]. The SphereLight $H$. pylori antibody J test used in the present study is also produced using antigens from $H$. pylori strains derived from Japanese patients and has been shown to have a high efficacy for diagnosis of infection [13-15]. Here, we investigated factors causing a negative result in that test in adult cases with endoscopic nodular gastritis. 
gooseflesh phenomenon, which is a common endoscopic manifestation of $H$. pylori infection in children [2$4,6]$. Miyamoto et al. observed nodular gastritis in $0.19 \%$ of 97,262 individuals aged 16 years and older who underwent an upper gastrointestinal endoscopy examination [1]. In the present study, of 17,727 individuals who underwent an upper gastrointestinal endoscopy as part of their medical checkup for screening, 147 $(0.83 \%)$ were diagnosed with nodular gastritis. Thus, the prevalence of this condition may be higher than previously reported and the majority of individuals affected by nodular gastritis may not have severe upper GI symptoms requiring a visit to a medical clinic. Although the prevalence of nodular gastritis shown by endoscopy is lower in adults as compared to children, the condition is recognized as a characteristic $H$. pylori-positive finding in all ages [1,5]. In addition, adults with this condition have been shown to have an increased risk of gastric cancer occurrence [27].

Based on the above information, we consider that an accurate diagnosis of $H$. pylori infection is very important, especially for adults with nodular gastritis. However, 8 (7.0\%) of the present 116 subjects with that condition had a negative result in a serum anti- $H$. pylori IgG antibody testing, although these cases were diagnosed as positive of $H$. pylori infection by additional diagnostic methods, such as urea breath test, histology, or following anti-H. pylori IgG antibody test. Thus, different diagnostic methods should be performed when the cases with nodular gastritis show negative results of serum anti- $H$. pylori IgG antibody testing. We noted that a mild degree of gastric mucosal atrophy tended to have a correlation with a negative serum anti-H. pylori IgG antibody test result in the present subjects with nodular gastritis, although this tendency was not observed by the multiple logistic regression analysis. It was also suggested by the results of our analysis of the pepsinogen I/II ratio, which reflects the degree of gastric mucosal atrophy [28,29]. Previous studies have noted that gastric mucosal atrophy progression is correlated with aging [17,28-29], while H. pylori infection generally occurs during childhood [30]. Therefore, the duration of $H$. pylori infection might have an effect on the serum titer of anti- $H$. pylori antibody test, though the age was not significantly different between subjects with and without a positive result in the present cohort. Future study is needed to investigate the adequate cutoff value in subjects with different gastric mucosal conditions, such as several degrees of mucosal atrophy and inflammation.

Another interesting observation in the present study was that the presence of spotty redness shown by endoscopy had a significant effect on serum anti-H. pylori IgG antibody test results. Spotty redness is an important endoscopic finding that reflects $H$. pylori infection-induced inflammation of gastric mucosa $[5,18$ 20]. A previous prospective multicenter study reported spotty redness in the gastric body in $70.3 \%$ of their subjects with an $\mathrm{H}$. pylori infection [5]. In the present investigation, that prevalence was 59.5\% in $116 \mathrm{H}$. pylori-positive subjects with nodular gastritis, a value lower in comparison with previous reports. An absence of spotty redness was well correlated with a negative finding in the serum anti- H. pylori antibody test. Furthermore, the level of pepsinogen II has been demonstrated to reflect the degree of gastric mucosal inflammation [29], while that in our subjects shown negative in antibody testing was significantly lower as compared to those with a positive result. Therefore, a low grade of gastric body mucosal inflammation is considered to be one of the important reasons that anti-H. pylori antibody test shows negative results in cases with nodular gastritis. Further study is needed to clarify the significance of spotty redness in subjects with $H$. pylori infection.

The present study has several limitations. We utilized a single serum anti-H. pylori IgG antibody test to evaluate the status of $H$. pylori infection and did not employ other diagnostic methods, as this was a retrospective analysis of individuals who visited a medical center for a detailed medical checkup. In addition, a majority of the present subjects were socially active and productive and considered to be socioeconomically middle class, thus young and elderly individuals were relatively few. Additional largescale investigations employing other types of anti-H. pylori IgG antibody tests are needed to clarify the present observations, especially in $H$. pylori-infected children, since the majority of those have been demonstrated to have nodular gastritis in endoscopic findings.

\section{Conclusions}

We analyzed the serum anti-H. pylori IgG antibody test result and several upper GI endoscopic findings in 116 subjects with nodular gastritis closely related to $H$. pylori infection. Eight of the investigated subjects showed negative results of serum anti-H. pylori IgG antibody test and endoscopic characteristics in those cases were mild degrees of gastric mucosal atrophy and absence of spotty redness in the gastric body and fornix, which may reflect the degree of gastric inflammation. Multiple logistic regression analysis revealed that the absence of spotty redness was a significant risk factor for a negative serum anti- $H$. pylori IgG antibody test result. It should be recognized that serum anti- $H$. pylori IgG antibody test is sometimes negative in cases with nodular gastritis when the endoscopic finding of spotty redness is not observed.

\section{Additional Information}

\section{Disclosures}

Human subjects: Consent was obtained or waived by all participants in this study. Ethics Committee of the Shimane Environment and Health Public Corporation issued approval IRB no. 2017-3. This study was performed in accordance with the Declaration of Helsinki, and the protocol was approved by the ethics committee of the Shimane Environment and Health Public Corporation (IRB no. 2017-3). Written informed 
consent indicating that clinical data would be used for a clinical study without the release of individual information was obtained from all subjects before performing the medical checkup examinations. Animal subjects: All authors have confirmed that this study did not involve animal subjects or tissue. Conflicts of interest: In compliance with the ICMJE uniform disclosure form, all authors declare the following: Payment/services info: All authors have declared that no financial support was received from any organization for the submitted work. Financial relationships: All authors have declared that they have no financial relationships at present or within the previous three years with any organizations that might have an interest in the submitted work. Other relationships: All authors have declared that there are no other relationships or activities that could appear to have influenced the submitted work.

\section{Acknowledgements}

We wish to thank Noriko Hara, Marie Ishida, Yuki Funaki, Noriko Yamauchi, Nanako Miura, Naoyuki Notsu, and Dai Takahashi of the Shimane Environment and Health Public Corporation, as well as Keiko Masuzaki of the Second Department of Internal Medicine, Shimane University Faculty of Medicine, for their helpful technical support.

\section{References}

1. Miyamoto M, Haruma K, Yoshihara M, et al.: Nodular gastritis in adults is caused by Helicobacter pylori infection. Dig Dis Sci. 2003, 48:968-75. 10.1023/a:1023016000096

2. De Giacomo C, Fiocca R, Villani L, et al.: Helicobacter pylori infection and chronic gastritis: clinical, serological, and histologic correlations in children treated with amoxicillin and colloidal bismuth subcitrate. J Pediatr Gastroenterol Nutr. 1990, 11:310-6.

3. Bujanover Y, Konikoff F, Baratz M: Nodular gastritis and Helicobacter pylori . J Pediatr Gastroenterol Nutr. 1990, 11:41-. 10.1097/00005176-199007000-00008

4. Raymond J, Bergeret M, Benhamou PH, Mensah K, Dupont C: A 2-year study of Helicobacter pylori in children. J Clin Microbiol. 1994, 32:461-3. 10.1128/jcm.32.2.461-463.1994

5. Kato T, Yagi N, Kamada T, Shimbo T, Watanabe H, Ida K: Diagnosis of Helicobacter pylori infection in gastric mucosa by endoscopic features: a multicenter prospective study. Dig Endosc. 2013, 25:508-18. 10.1111/den.12031

6. Yang HR: Updates on the diagnosis of Helicobacter pylori infection in children: what are the differences between adults and children?. Pediatr Gastroenterol Hepatol Nutr. 2016, 19:96-103. 10.5223/pghn.2016.19.2.96

7. Correa P, Houghton J: Carcinogenesis of Helicobacter pylori. Gastroenterology. 2007, 133:659-72. 10.1053/j.gastro.2007.06.026

8. Bayerdörffer E, Neubauer A, Rudolph B, et al.: Regression of primary gastric lymphoma of mucosaassociated lymphoid tissue type after cure of Helicobacter pylori infection. Lancet. 1995, 345:1591-4. 10.1016/s0140-6736(95)90113-2

9. Uemura N, Okamoto S, Yamamoto S, et al.: Helicobacter pylori infection and the development of gastric cancer. N Engl J Med. 2001, 345:784-9. 10.1056/NEJMoa001999

10. Vaira D, Holton J, Menegatti M, Ricci C, Gatta L, Geminiani A, Miglioli M: Review article: invasive and noninvasive tests for Helicobacter pylori infection. Aliment Pharmacol Ther. 2000, 14 Suppl 3:13-22. 10.1046/j.1365-2036.2000.00096.x

11. Ishihara S, Kaji T, Kawamura A, et al.: Diagnostic accuracy of a new non-invasive enzyme immunoassay for detecting Helicobacter pylori in stools after eradication therapy. Aliment Pharmacol Ther. 2000, 14:611-4. 10.1046/j.1365-2036.2000.00736.x

12. Adachi K, Kawamura A, Ono M, et al.: Comparative evaluation of urine-based and other minimally invasive methods for the diagnosis of Helicobacter pylori infection. J Gastroenterol. 2002, 37:703-8. $10.1007 /$ s005350200115

13. Kita M, Take S, Okada H, Matsushita O, Yokota K: A study to determine the optimum antigens for the serodiagnosis of Helicobacter pylori infection in Japanese patients and the association with IgG subclass and gastric cancer. Rinsho Byori. 2015, 63:180-6.

14. Karasawa H, Sugiyama A, Takeda M, et al.: ABC classification of gastric cancer risk based on a new kit to detect serum Helicobacter pylori antibodies: comparison with another antibody detection kit. J Gastrointestinal Cancer Screen. 2016, 54:18-29.

15. Adachi K, Mishiro T, Tanaka S, Kinoshita Y: Analysis of negative result in serum anti-H. pylori IgG antibody test in cases with gastric mucosal atrophy. J Clin Biochem Nutr. 2016, 59:145-8. 10.3164/jcbn.16-13

16. Aoyama N, Shigeta S, Yokozaki H: Evaluation of $6 \mathrm{H}$. pylori antibody serological diagnosis kits using the same samples strictly diagnosed the status of H. pylori infection. Jpn J Helicobacter Res. 2020, 21:112-20.

17. Kimura K, Takemoto $\mathrm{T}$ : An endoscopic recognition of the atrophic border and its significance in chronic gastritis. Endoscopy. 1969, 1:87-97. 10.1055/s-0028-1098086

18. Haruma K: Kyoto classification of gastritis. Nihon Medical Center, Tokyo; 2017.

19. Watanabe K, Nagata N, Nakashima R, et al.: Predictive findings for Helicobacter pylori-uninfected, -infected and -eradicated gastric mucosa: validation study. World J Gastroenterol. 2013, 19:4374-9. 10.3748/wig.v19.i27.4374

20. Kamada T, Haruma K, Inoue K, Shiotani A: [Helicobacter pylori infection and endoscopic gastritis -Kyoto classification of gastritis]. Nihon Shokakibyo Gakkai Zasshi. 2015, 112:982-3. 10.11405/nisshoshi.112.982

21. Miwa H, Sakaki N, Sugano K, et al.: Recurrent peptic ulcers in patients following successful Helicobacter pylori eradication: a multicenter study of 4940 patients. Helicobacter. 2004, 9:9-16. 10.1111/j.10834389.2004.00194.x

22. Fukase K, Kato M, Kikuchi S, et al.: Effect of eradication of Helicobacter pylori on incidence of metachronous gastric carcinoma after endoscopic resection of early gastric cancer: an open-label, 


\section{Cureus}

randomised controlled trial. Lancet. 2008, 372:392-7. 10.1016/S0140-6736(08)61159

23. Take S, Mizuno M, Ishiki K, et al.: Seventeen-year effects of eradicating Helicobacter pylori on the prevention of gastric cancer in patients with peptic ulcer; a prospective cohort study. J Gastroenterol. 2015, 50:638-44. 10.1007/s00535-014-1004-5

24. Marchildon PA, Sugiyama T, Fukuda Y, Peacock JS, Asaka M, Shimoyama T, Graham DY: Evaluation of the effects of strain-specific antigen variation on the accuracy of serologic diagnosis of Helicobacter pylori infection. J Clin Microbiol. 2003, 41:1480-5. 10.1128/JCM.41.4.1480-1485.2003

25. Matsuo K, Hamajima N, Tominaga S, et al.: Helicobacter pylori IgG antibody test established in the United States showed a substantially lower sensitivity for Japanese population. Am J Gastroenterol. 2000, 95:15978. 10.1111/j.1572-0241.2000.02111.x

26. Okuda M, Sugiyama T, Fukunaga K, Kondou M, Miyashiro E, Nakazawa T: A strain-specific antigen in Japanese Helicobacter pylori recognized in sera of Japanese children. Clin Diagn Lab Immunol. 2005, 12:1280-4. 10.1128/CDLI.12.11.1280-1284.2005

27. Kamada T, Hata J, Tanaka A, et al.: Nodular gastritis and gastric cancer . Dig. Endosc. 2006, 18:79-83. 10.1111/j.1443-1661.2006.00588.x

28. Miki K, Ichinose M, Ishikawa KB, et al.: Clinical application of serum pepsinogen I and II levels for mass screening to detect gastric cancer. Jpn J Cancer Res. 1993, 84:1086-90. 10.1111/j.1349-7006.1993.tb02805.X

29. Kiyohira K, Yoshihara M, Ito M, Haruma K, Tanaka S, Chayama K: Serum pepsinogen concentration as a marker of Helicobacter pyloriinfection and the histologic grade of gastritis; evaluation of gastric mucosa by serum pepsinogen levels. J Gastroenterol. 2003, 38:332-8. 10.1007/s005350300060

30. Asaka M, Kimura T, Kudo M, et al.: Relationship of Helicobacter pylori to serum pepsinogens in an asymptomatic Japanese population. Gastroenterology. 1992, 102:760-6. 10.1016/0016-5085(92)90156-S 